\title{
Preparation of hydrophobic nanofibers by electrospinning of PMMA dissolved in
}

\section{2-propanol and water}

\author{
Hui-Yi Chang, Chao-Ching Chang ${ }^{a}$, Liao-Ping Cheng \\ Department of Chemical and Materials Engineering, Tamkang University, New Taipei City, Taiwan, ROC
}

\begin{abstract}
In this study, we adopted rubbing alcohol (2-propanol/water $=7.8 / 2)$ as the solvent to prepare hydrophobic poly(methyl methacrylate) (PMMA) nanofibers (with submicron scale diameters) by electrospinning. In the literature, the general solvents, such as acetone, tetrahydrofuran, chloroform, toluene, etc., to dissolve PMMA are harmful and not environmentally friendly. 2-Propanol and water are both not hazardous to humans and the environment. PMMA dissolved in rubbing alcohol can be electrospun near room temperature. The solutions were heated at $\sim 60{ }^{\circ} \mathrm{C}$ and allowed to cool to room temperature. Controlling the solution concentration and electrospinning parameters, fibers with diameters of $0.65 \sim 0.85 \mu \mathrm{m}$ were obtained. The electrospun PMMA mats were hydrophobic with contact angles > $130^{\circ}$ and showed good water resistance.
\end{abstract}

\section{Introduction}

Electrospinning is a technique which draws polymer solutions or polymer melts to submicro- or nanofibers. Due to the advantages of spun fibers, such as high porosity and high ratio of surface area to volume, electrospinning has shown significant potential for tissue engineering, drug delivery, filtration, sensors, fuel cells, photoelectric devices, and other applications [1,2]. For environment-friendly processes and stable long-time-use products, it is necessary to consider seriously the polymer and solvent used for fiber spinning. Water-soluble and hydrophilic polymers can be dissolved in water, alcohols or their mixtures, but the spun fibers do not possess ${ }^{\mathrm{a} C}$ Corresponding author: ccchang@tku.edu.tw moisture resistance. Thus they are limited to temporary use and then removed in water. After absorbing water, the fibers will reduce or lose their functions due to the structural deformation, even gradually dissolve in the water.

Poly(methyl methacrylate) (PMMA) is a hydrophobic and common material. PMMA submicro- and nanofibers prepared by electrospinning have been studied and shown potential for tissue engineering and biomaterials [3-6]. The common solvents, such as acetone, tetrahydrofuran, chloroform, toluene, etc., to dissolve PMMA are harmful and not environmentally friendly. The solubility of hydrophobic polymers in water or alcohols is often very low. However, 2-propanol mixed with water, i.e., rubbing 
alcohol, dissolves some hydrophobic polymers, including PMMA. 2-Propanol and water are not hazardous to humans and the environment. It has been known that PMMA can be dissolved in rubbing alcohol with particular ratios of 2-propanol and water [7]. In this study, PMMA-rubbing alcohol solutions were prepared and electrospun. Controlling the PMMA concentration and electrospinning parameters, PMMA fibers with diameters of $0.65 \sim 0.85 \mu \mathrm{m}$ were obtained. The electrospun mats were hydrophobic with contact angles $>130^{\circ}$ and showed good resistance.

\section{Experimental Section}

\subsection{Materials}

Poly(methyl methacrylate) (PMMA) was purchased from Sigma-Aldrich (weight-average molar weight of 120,000 $\mathrm{g} / \mathrm{mol}$ ) and Alfa-aesar (weight-average molar weight of 400,000 g/mol). 2-Propanol with purity over 99.5\% was purchased from J.T. Baker. Deionized water and distilled water were obtained from laboratory. All chemicals were used as received.

\subsection{Preparation of PMMA fibers}

The polymer solution was prepared by dissolving PMMA in rubbing alcohol (2-propanol : water $=7.8: 2, \mathrm{w} / \mathrm{w})$, stirring at $\sim 60{ }^{\circ} \mathrm{C}$ for 1 hour, and then cooling to room temperature. A vertical electrospinning setup (Falco Tech Enterprise Co., Ltd, Taiwan) was used. The PMMA solution was in a $5 \mathrm{~mL}$ plastic syringe, and a syringe pump (New Era Pump Systems, Inc.) was used to promote the solution. The syringe was connected to a needle (inner diameter of $0.42 \mathrm{~mm}$ ) through a Teflon capillary tube. A stainless steel plate covered with aluminum foil was employed as collector $(12 \mathrm{~cm}$ below the needle). An electric field between the needle and collector was generated using a high voltage power supply. The temperature was maintained at $30^{\circ} \mathrm{C}$ and the relative humidity was about $45 \%$.

\subsection{Fiber analysis}

The sub-microfibers were observed by a field emission scanning electron microscope (FE-SEM, Hitachi S-4800), and the diameter of the fibers was calculated by using software Image $\mathrm{J}$ based on the SEM images. The contact angle of water on the mat surface was measured by a contact angle goniometer (FTA-125, First Ten Angstroms) at room temperature. A $3 \mu \mathrm{L}$ drop of water was placed onto the mat surface. The image was taken and the contact angle was measured by means of shape analysis of the sessile drop.

\section{Results and Discussion}

Shenoy et al. [8,9] proposed a semi-empirical formula [equation (1)] to predict the result of electrospinning. The solution entanglement number $\left(n_{\mathrm{e}}\right)_{\text {soln }}$ is defined as the ratio of the weight-average molecular weight $\left(M_{\mathrm{w}}\right)$ to the entanglement molecular weight in solution $\left(\left(M_{\mathrm{e}}\right)_{\text {soln }}\right)$. The latter can be calculated by means of the polymer volume fraction $\left(\phi_{\mathrm{p}}\right)$ and the entanglement molecular weight in melt $\left(M_{\mathrm{e}}\right)$.

$$
\begin{gathered}
\left(\mathrm{n}_{e}\right)_{\text {soln }}=\frac{M_{w}}{\left(M_{e}\right)_{\text {soln }}}=\frac{\left(\emptyset_{p} M_{w}\right)}{M_{e}} \\
\emptyset_{p}=\frac{\frac{\text { polymerweight }(\mathrm{g})}{\text { polymer density }\left(\mathrm{g} / \mathrm{cm}^{3}\right)}}{\frac{\text { polymerweight }(\mathrm{g})}{\text { polymer density }\left(\mathrm{g} / \mathrm{cm}^{3}\right)}+\frac{\text { solvent weight }(\mathrm{g})}{\text { solvent density }\left(\mathrm{g} / \mathrm{cm}^{3}\right)}}
\end{gathered}
$$

When $n_{\mathrm{e}}<2$, only beaded morphology is predicted; when $n_{\mathrm{e}}>3.5$, complete fiber formation is predicted. On the basis of equation (1), complete PMMA fibers will appear at concentrations of $42 \mathrm{wt} \%$ and $13.5 \mathrm{wt} \%$ for PMMA with $\mathrm{M}_{\mathrm{w}} \sim 120,000$ and $\mathrm{M}_{\mathrm{w}} \sim 400,000$, respectively (Figure 1). However, in this study the experiment results did not agree with such calculated results. 


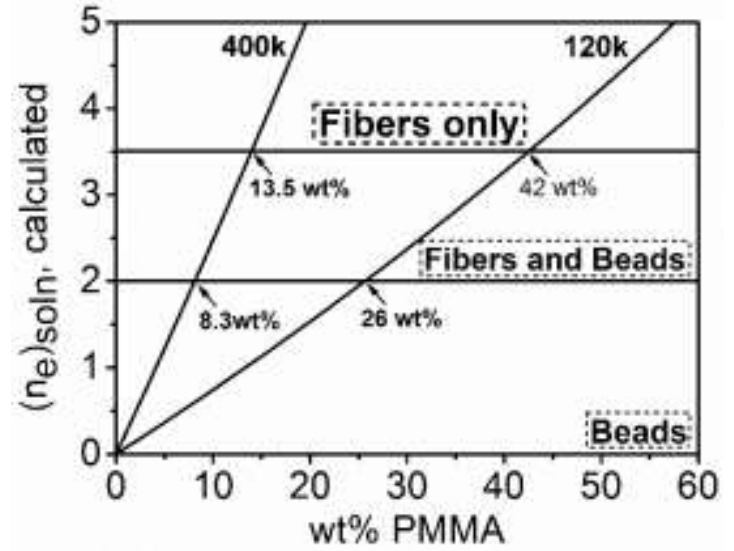

Figure 1. The calculated solution entanglement number $\left(n_{\mathrm{e}}\right)_{\text {soln }}$ as a function of concentration for PMMA in IPA/water.

Solutions of PMMA with $\mathrm{M}_{\mathrm{w}} \sim 120,000$ volatilized too rapidly to be electrospun successfully. All beads were observed at $5 \mathrm{wt} \%$, and the beads and fibers was observed at $8 \mathrm{wt} \%$ (Figure 2). Solutions gelled at the tip of the needle quickly at higher concentrations. Beads and fibers also appeared at $1 \mathrm{wt} \%$ of PMMA with $\mathrm{M}_{\mathrm{w}} \sim 400,000$ (Figure 2). However, good beads-free fibers appeared when the concentration reached $1.5 \mathrm{wt} \%$. The fibers were straight and the mat was uniform (Figure 3).
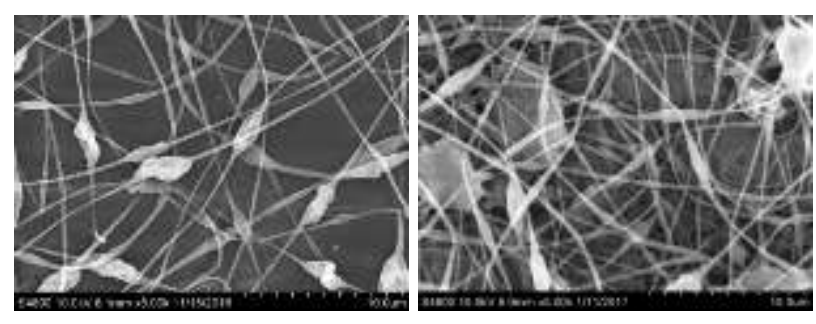

Figure 2. SEM images of PMMA fibers from PMMA solutions: (left) $\mathrm{M}_{\mathrm{w}} \sim 120,000,8 \mathrm{wt} \%$; (right) $\mathrm{M}_{\mathrm{w}} \sim 400,000,1 \mathrm{wt} \%$.

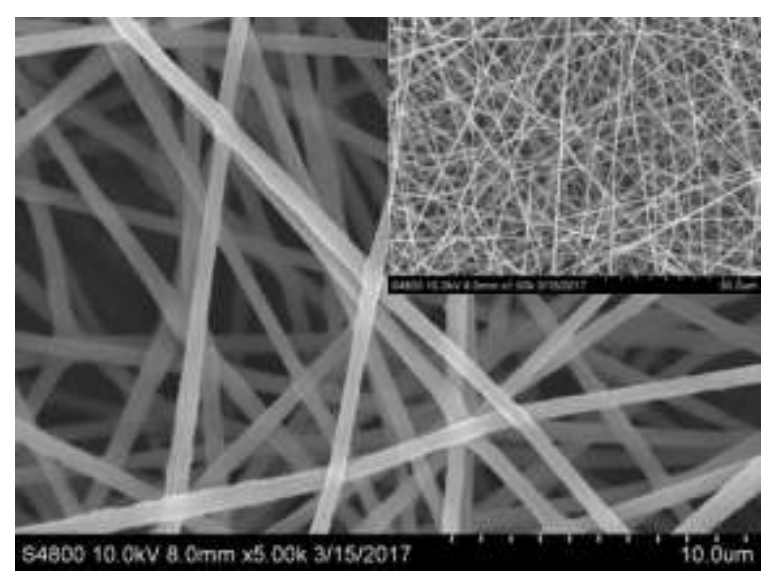

Figure 3. SEM image of PMMA fibers from the $1.5 \mathrm{wt} \%$ PMMA $\left(\mathrm{M}_{\mathrm{w}} \sim 400,000\right)$ solution.
Because electrospinning is operated by counteracting of electrostatic repulsion to surface tension, conductivity of the solvent is also a significant factor. Thus the effect of water quality on the fiber diameter was studied. Conductivities of distilled water and deionized water were 1.2 and $1.92 \mu \mathrm{S} / \mathrm{cm}$, respectively. When the flow rate and voltage were kept at $0.05 \mathrm{~mL} / \mathrm{min}$ and $7.1 \mathrm{kV}$, the average diameters of the formed fibers were $770 \pm 45$ $\mathrm{nm}$ (distilled water) and $650 \pm 46 \mathrm{~nm}$ (deionized water). A higher conductivity of a solvent equals to more charge density. As the charges are introduced by applying high voltage, the repulsion of charges will stretch the jet, which causes narrower fibers. The effect of voltage on the fiber diameter was also studied. The average diameters were $837 \pm 139$ and $770 \pm 45 \mathrm{~nm}$ for 5.5 and $7.1 \mathrm{kV}$, respectively. A high voltage gave a small average diameter and also a narrow diameter distribution. The result showed that the required diameters for different applications can be controlled by changing voltage.

PMMA is a hydrophobic polymer. Although it was dissolved in rubbing alcohol and then spun, the characteristic of hydrophobicity was not changed. Through the contact angle test, the mats achieved water contact angles $>130^{\circ}$. The water-resistant property was also tested. A drop of tap water was dropped on the mat surface, and kept it for $10 \mathrm{~min}$ in order to understand the water resistance of the form fibers. The morphologies of the fibers before and after wetting were observed by SEM (Figure 4). After wetting, the fibers were not dissolved in water. Besides, there was not remarkable damage or deformation of the fibers.

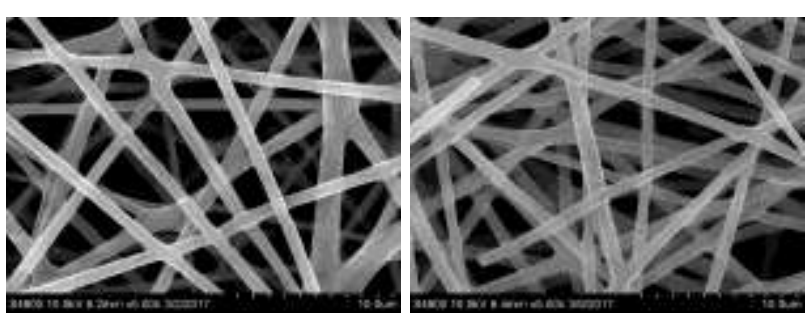

Figure 4. SEM images of PMMA fibers before (left) and after (right) wetting. 


\section{Conclusion}

In this study, preparation of hydrophobic PMMA submicrofibers by electrospinning was demonstrated. An environmentally friendly solvent, i.e., rubbing alcohol (2-propanol/water $=7.8 / 2$ ), was used to dissolve PMMA, and the solution was electrospun by controlling several parameters. Due to the high volatilization of the solution, PMMA with $\mathrm{M}_{\mathrm{w}} \sim 120,000$ cannot be electrospun successfully. However, beads-free fibers can be formed when the concentration of PMMA with $\mathrm{M}_{\mathrm{w}} \sim 400,000$ reached $1.5 \mathrm{wt} \%$. Raising the voltage in electrospinning or conductivity of the solution will decrease the average diameter of the formed fibers. The PMMA mats were hydrophobic with contact angles $>130^{\circ}$ and showed good water resistance.

\section{References}

1. N. Bhardwaj, S.C. Kundu, Biotechnol. Adv., 28, 325-347 (2010)

2. C.J. Luo, S.D. Stoyanov, E. Stride, E. Pelan, M. Edirisinghe, Chem. Soc. Rev., 41, 4708-4735 (2012)

3. S. Piperno, L. Lozzi, R. Rastelli, M. Passacantando, S. Santucci, Appl. Surf. Sci., 252, 5583-5586 (2006)

4. Y.F. Qian, Y. Su, X.Q. Li, H.S. Wang, C.L. He, Iran. Polym. J., 19, 123-129 (2010)

5. Y. Liu, Y. Ji, K. Ghosh, R.A.F. Clark, L. Huang, M.H. Rafailovichz, J. Biomed. Mater. Res., Part A, 90A, 1092-1106 (2009)

6. J.J. Miao, R.C. Pangule, E.E. Paskaleva, E.E. Hwang, R.S. Kane, R.J. Linhardt, J.S. Dordick, Biomaterials, 32, 9557-9567 (2011)

7. L.P. Cheng, H.Y. Shaw, J. Polym. Sci., Part B: Polym. Phys., 38, 747-754 (2000)
8. S.L. Shenoy, W.D. Bates, H.L. Frisch, G.E. Wnek, Polymer, 46, 3372-3384 (2005)

9. S.L. Shenoy, W.D. Bates, G. Wnek, Polymer, 46, 8990-9004 (2005) 